\title{
Ganoderic Acid A suppresses the phenotypic modulation of pulmonary artery smooth muscle cells through the inactivation of PI3K/Akt pathway in pulmonary arterial hypertension
}

\author{
Yan MENG ${ }^{1 \&}$, Qian NING ${ }^{2 \&}$, Ya LIU ${ }^{2 *}$ (D), Yamei PANG ${ }^{2}$, Hui REN² ${ }^{2}$ Tian YANG ${ }^{2}$, Hong $\mathrm{LI}^{2}$, Shaojun $\mathrm{LI}^{2}$
}

\begin{abstract}
Ganoderic acid A (GAA) is one of the most abundant triterpenoids in Ganoderma lucidum and has protective effect on several vascular diseases. However, the effect of GAA on pulmonary arterial hypertension (PAH) has not been reported. The aim of this study was to investigate the effect of the GAA on the hypoxia-induced phenotypic modulation of PASMCs and the involved transduction pathway. Primary rat pulmonary artery smooth muscle cells (PASMCs) were isolated and cultured under hypoxia condition to induce phenotypic modulation. Our results showed that hypoxia significantly increased the proliferation and migration of PASMCs, as well as inhibited the apoptosis of PASMCs, which were blocked by GAA treatment. In addition, hypoxia-induced dedifferentiation of PASMCs was prevented by GAA with increased the expression levels of myocardin and calponin, and decreased the expression of osteopontin (OPN). Furthermore, GAA suppressed the hypoxia-induced expression of p-PI3K and p-Akt in PASMCs. Treatment with IGF-1 reversed the effects of GAA on proliferation, migration, apoptosis and dedifferentiation in hypoxia-treated PASMCs. Taken together, these findings demonstrated that GAA suppresses the phenotypic modulation of PASMCs through the inactivation of PI3K/Akt pathway. Thus, GAA may be a potent therapeutic agent for PAH in future clinical practice.
\end{abstract}

Keywords: Ganoderic Acid A (GAA); Pulmonary Arterial Hypertension (PAH); Pulmonary Artery Smooth Muscle Cells (PASMCs); phenotypic modulation; PI3K/Akt pathway.

Practical Application: GAA may be a potent therapeutic agent for PAH in future clinical practice.

\section{Introduction}

Pulmonary arterial hypertension (PAH) is a progressive vascular disease with an estimated prevalence of 15 cases per million (Awdish \& Cajigas, 2016). PAH is characterized by increased pulmonary vascular resistance (PVR) that leads to elevated pulmonary arterial pressure and right heart failure (Coons et al., 2019). An improved understanding of the pathophysiology of $\mathrm{PAH}$ has revealed that sustained vasoconstriction, abnormal progressive fixed vascular remodeling, accompanied by endothelial dysfunction and activation of fibroblasts and smooth muscle cells are involved in the pathogenesis of PAH (Lan et al., 2018; Montani et al., 2014).

Biomedical advances over the last decade have identified the central role of proliferative pulmonary arterial smooth muscle cells (PASMCs) in the development of PAH (He et al., 2020; Hu et al., 2015). There is a tendency to think that excessive proliferation and resistance to apoptosis of PASMCs is the crucial component of pulmonary vascular remodeling (He et al., 2020). Different triggers have been described to lead to uncontrolled PASMCs, such as inflammation, hypoxia and shear stress or vascular injury. Among these, it is increasingly believed that prolonged exposure to hypoxia at high altitude leads to PAH development through affecting the phenotype of PASMCs (Veith et al., 2016).

Ganoderic acid A (GAA) is one of the most abundant triterpenoids in Ganoderma lucidum, which is a potent pharmacological macrofungus usually used as an alternative adjuvant in the treatment of leukemia, carcinoma, vascular diseases, hepatitis and diabetes (Ahmad, 2018; Sanodiya et al., 2009). GAA has been reported to have various pharmacological actions, such as anti-oxidative, anti-inflammatory and anti-tumor (Chi et al., 2018; Gill et al., 2016; Kang et al., 2020). Recently, GAA was reported to exert protective effect on hypoxia-related vascular diseases. GAA alleviates myocardial ischemia-reperfusion injury through its anti-oxidative and anti-inflammatory activities in rats (Zhang et al., 2020). GAA protects rat H9c2 cardiomyocytes from hypoxia-induced viability loss, proliferation inhibition and apoptosis via up-regulating miR-182-5p (Zhang et al., 2018). However, the role of GAA in PAH remains unclear. The aim of this study was to investigate the effect of the GAA on the hypoxia-induced PASMCs and the involved transduction pathway. 


\section{Materials and methods}

\subsection{Cell culture and hypoxia treatment}

Primary rat pulmonary artery smooth muscle cells (PASMCs) were isolated from rat pulmonary arteries as previous described (Barman \& Marrero, 2005). The PASMCs were grown at $37^{\circ} \mathrm{C}$ in an incubator with $5 \% \mathrm{CO}_{2}$ for 3-5 days. The cells from passage 3-6 were used for the further experiments. The PASMCs in control group were incubated with a constant supply of air containing $21 \% \mathrm{O}_{2}$ and $5 \% \mathrm{CO}_{2}$ at $37^{\circ} \mathrm{C}$. The PASMCs in hypoxia-treated group were incubated with a gas mixture containing $3 \% \mathrm{O}_{2}$ and $5 \% \mathrm{CO}_{2}$. The PASMCs in GAA-treated group were incubated with $20 \mu \mathrm{M}$ GAA (Sigma-Aldrich, St. Louis, MO, USA) under hypoxia condition. The PASMCs in IGF-1-treated group were incubated with $10 \mathrm{ng} / \mathrm{ml}$ IGF-1 (R\&D Systems, Minneapolis, $\mathrm{MN}, \mathrm{USA}$ ) and $20 \mu \mathrm{M}$ GAA under hypoxia condition.

\subsection{Cell cytotoxicity assay}

$\mathrm{LDH}$ released from PASMCs was measured using a Cytotoxicity LDH Assay Kit (Dojindo, Kumamoto, Japan) following the manufacturer's instructions. After treatment with various concentrations of GAA $(0,5,10,20$ and $40 \mu \mathrm{M})$ for $24 \mathrm{~h}$, the cells were added with $100 \mu \mathrm{L}$ of working solution containing water-soluble tetrazolium salt and incubated at room temperature for $30 \mathrm{~min}$. Then $50 \mu \mathrm{L}$ stop solution was added to each well and the absorbance at $490 \mathrm{nM}$ was measured using a spectrophotometer (SpectraMax M5, Molecular Devices, Sunnyvale, CA, USA).

\subsection{Cell proliferation assay}

Proliferation of PASMCs was evaluated after indicated treatmetns using the MTT (3-(4,5-dimethylthiazol-2-yl)-2,5diphenyl tetrazolium bromide) assay. Briefly, PASMCs were plated on 96-well plates with the density of $2 \times 10^{4}$ cells/well and cultured in normoxia or hypoxia condition for $24 \mathrm{~h}$. Cells were added with $20 \mu \mathrm{L}$ MTT solution (MP Biomedicals, Santa Ana, CA, USA) at a final concentration of $5 \mathrm{mg} / \mathrm{mL}$. After $4 \mathrm{~h}$ incubation, the formazan was dissolved by DMSO. The optical density (OD) was measured at $490 \mathrm{nM}$ using an ELISA plate reader (Bio-Tek Instruments, Winooski, VT, USA).

\subsection{Cell migration assay}

PASMCs in serum-free media were seeded onto the upper transwell chamber, while the lower chamber was loaded with complete medium, which acts as a chemotactic attractant. After incubation for $24 \mathrm{~h}$, non-migrating cells were removed from the upper surface of the chamber insert with a cotton swab. The migrating cells were fixed with methanol and stained with $0.1 \%$ crystal violet (Sigma). Cells from at least five different fields were counted under an Olympus IX71 inverted microscope $(\times$ 200, Olympus, Tokyo, Japan).

\subsection{Cell apoptosis assay}

For apoptosis assay, Caspase 3 activity was detected with Caspase 3 activity assay kit (Beyotime) per the manufacturer's instructions. Briefly, the treated PASMCs were lysed and incubated with the substrate Ac-DEVD-pNA $(2 \mathrm{mM})$ at $37^{\circ} \mathrm{C}$ for $1 \mathrm{~h}$. Then the absorbance values were read at $405 \mathrm{nM}$.

\subsection{Western blot}

Total proteins from PASMCs were isolated using the ProteinExt Mammalian Total Protein Extraction Kit (TransGen Biotech, Beijing, China), followed by the determination of protein concentrations using a Pierce BCA protein assay kit (Thermo, Carlsbad, CA, USA). The targeted protein levels were determined by western blot analysis as previously described (Dai et al., 2018). Antibodies used in the study were: myocardin, calponin, osteopontin (OPN), Akt, p-Akt, PI3K, p-PI3K, $\beta$-actin and horseradish peroxidase (HRP)-conjugated secondary antibody. The blots on membranes were visualized using enhanced chemiluminescence reagent (Pierce Biotechnology, IL, USA).

\subsection{Statistical analysis}

The results are analyzed by SPSS version 13.0 software (SPSS Inc., Chicago, IL, USA) and finally presented as means \pm SD. One-way ANOVA was used to calculate differences among the various study groups. $p<0.05$ was considered statistically significant.

\section{Results}

\subsection{GAA inhibits hypoxia-induced proliferation and migration of PASMCs}

First, we evaluated the cytotoxicity effect of GAA with different dosages $(0,5,10,20,40 \mu \mathrm{M})$ on PASMCs. GAA at the concentration of $40 \mu \mathrm{M}$ induced the $\mathrm{LDH}$ release of PASMCs with statistically significant difference (Figure 1A). The concentration of $20 \mu \mathrm{M}$ was selected for the following experiments. MTT assay indicated that PASMCs pretreated with GAA inhibited hypoxiainduced proliferation of PASMCs (Figure 1B). Increased cell migration of hypoxia-induced PASMCs was also reduced by GAA treatment (Figure 1C).

\subsection{GAA promotes cell apoptosis in hypoxia-induced PASMCs}

To evaluate the effect of GAA on cell apoptosis, the caspase- 3 activity was detected. In hypoxia-stimulated PASMCs, the caspase-3 activity was markedly decreased as compared to control PASMCs. After treatment with $20 \mu \mathrm{M}$ GAA, the caspase-3 activity was dramatically increased (Figure 2).

\subsection{GAA regulates hypoxia-induced dedifferentiation of PASMCS}

After exposure to hypoxia condition, PASMCs spontaneously underwent dedifferentiation with decreased the protein expression levels of myocardin and calponin, as well as increased the protein expression level of OPN, as compared to PASMCs cultured under normal condition. However, treatment with GAA to PASMCs in hypoxia induced the protein expression levels of myocardin 
A

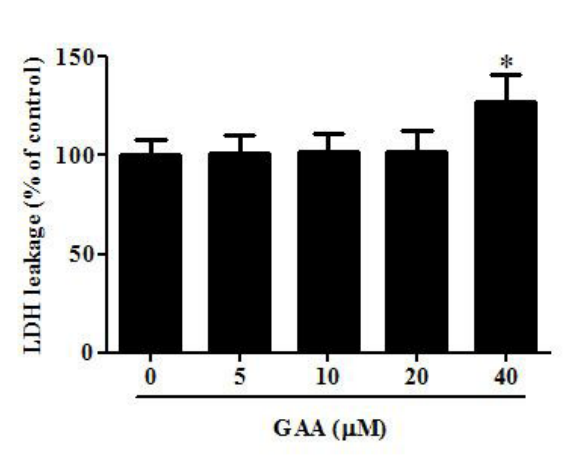

C

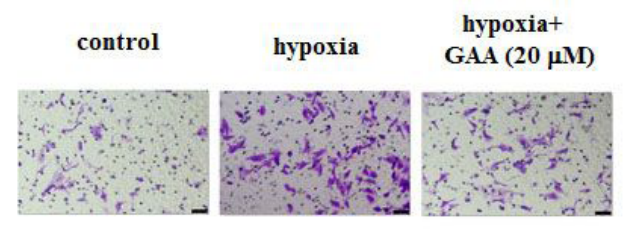

B
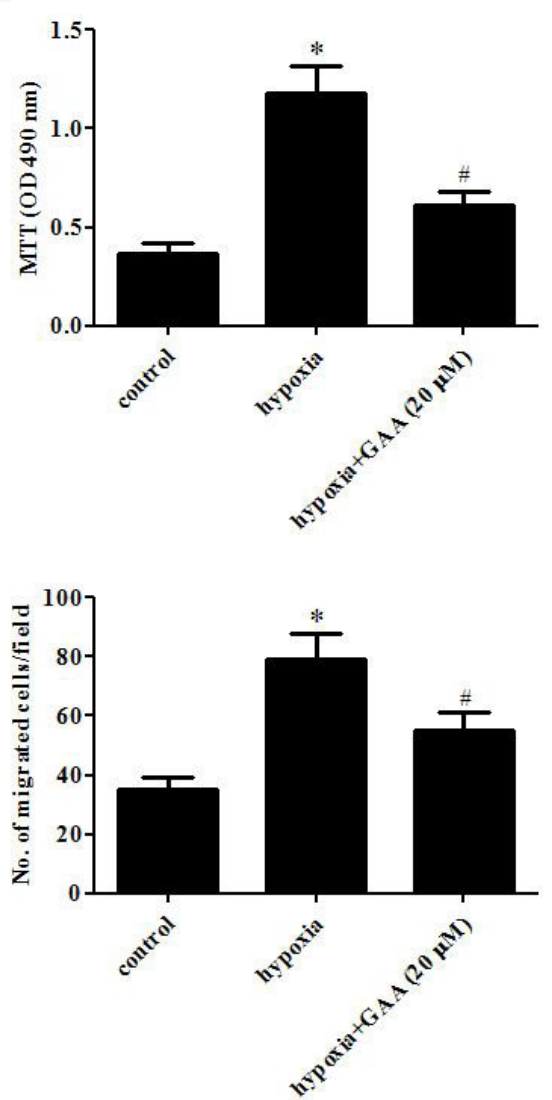

Figure 1. GAA inhibits proliferation and migration of PASMCs in response to hypoxia. (A) LDH release of PASMCs after treatment with different dosages of GAA $(0,5,10,20,40 \mu \mathrm{M})$ for $24 \mathrm{~h}$. PASMCs were treated with $20 \mu \mathrm{M}$ GAA for 24 h then exposed to hypoxia condition; (B) MTT assay for the proliferation of PASMCs; (C) Transwell assay for the migration of PASMCs. ${ }^{*} p<0.05$ versus control group; ${ }^{*} p<0.05$ versus hypoxiatreated group.

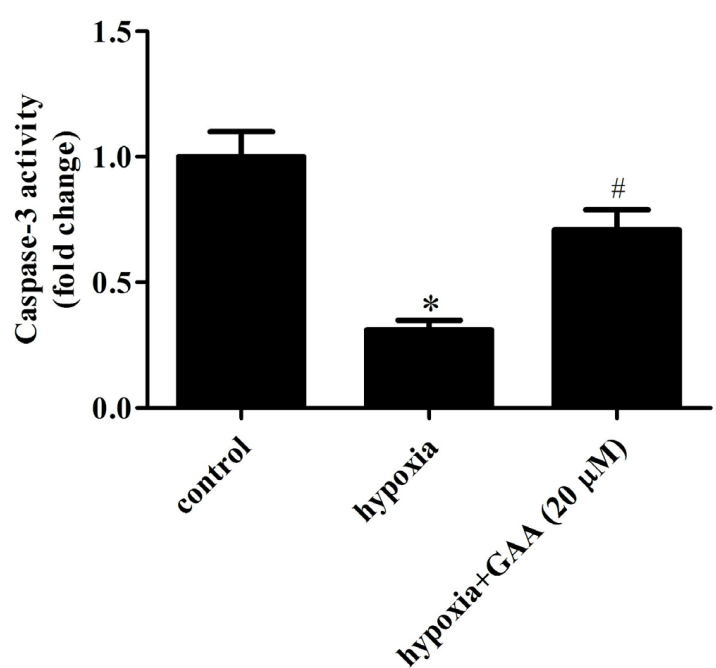

Figure 2. GAA promotes cell apoptosis of PASMCs in response to hypoxia. PASMCs were treated with $20 \mu \mathrm{M}$ GAA for $24 \mathrm{~h}$ then exposed to hypoxia condition. Cell apoptosis was measured using capase-3 activity ELISA kit. ${ }^{*} p<0.05$ versus control group; ${ }^{*} p<0.05$ versus hypoxia-treated group. and calponin and suppressed the protein expression level of OPN (Figure 3A-D).

\subsection{GAA inhibits hypoxia-induced activation of PI3K/Akt in PASMCs}

Since PI3K/Akt signaling pathway has been reported to be involved in the hypoxia-induced PASMCs, the effect of GAA on PI3K/Akt was evaluated by western blot. We compared the expression levels of PI3K, p-PI3K, Akt, and p-Akt in different groups. Hypoxia-induced PASMCs showed significant increases in the expression of $\mathrm{p}-\mathrm{PI} 3 \mathrm{~K}$ and $\mathrm{p}$-Akt. We also found that the increased expression levels of p-PI3K and p-Akt were prevented by GAA (Figure 4 ).

\subsection{IGF-1 treatment reverses the effects of GAA on proliferation, migration and apoptosis in PASMCs}

To further confirm the role of PI3K/Akt, we used IGF-1 to block the GAA-caused inhibitory effect on PI3K/Akt. The data obtained from the MTT assay showed that IGF-1 reversed the reduced cell proliferation in GAA-treated PASMCs (Figure 5A). In addition, we found that IGF-1 also reversed the effects of 

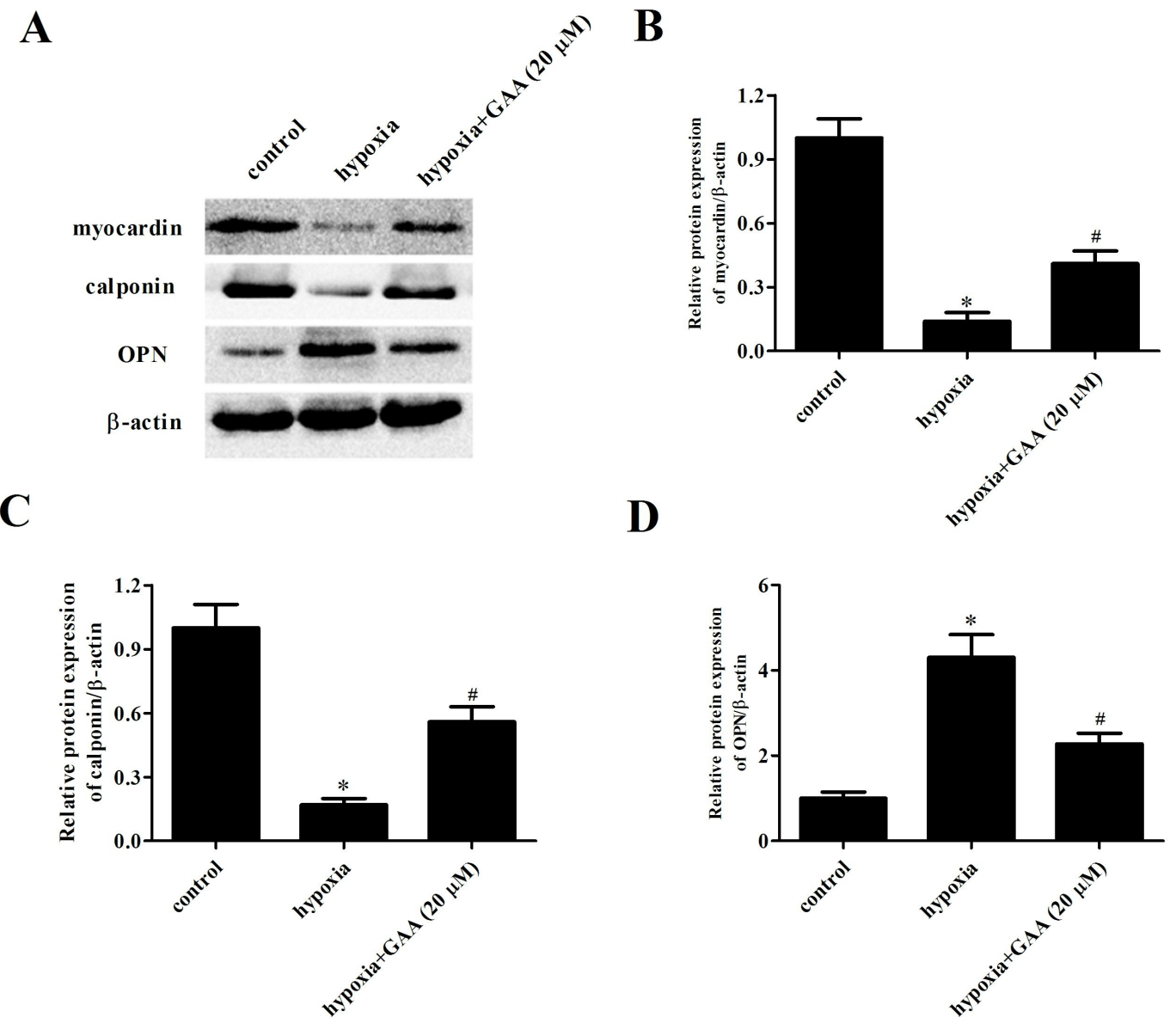

Figure 3. GAA regulates hypoxia-induced dedifferentiation of PASMCs. PASMCs were treated with $20 \mu \mathrm{M}$ GAA for 24 h then exposed to hypoxia condition. (A) Western blot analysis for the relative protein levels of contractile phenotype markers myocardin and calponin and synthetic phenotype marker OPN; (B-D) Quantification analysis of myocardin, calponin and OPN. ${ }^{*} p<0.05$ versus control group; ${ }^{*} p<0.05$ versus hypoxia-treated group.

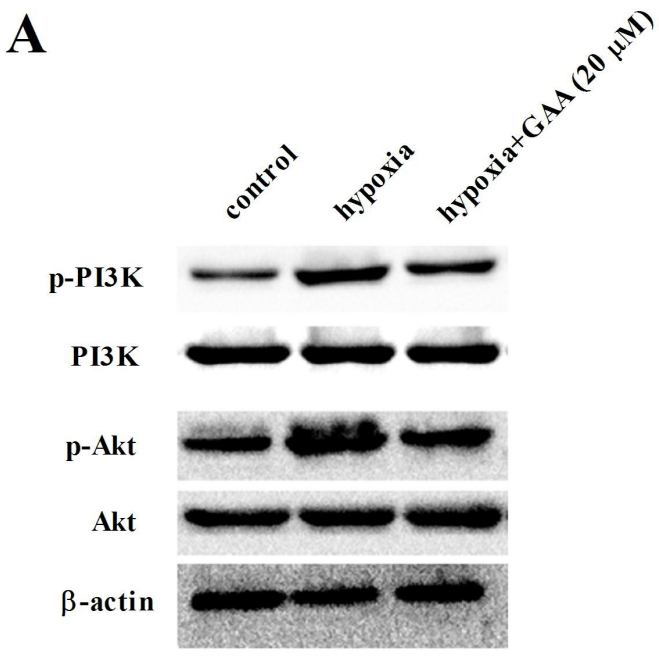

\section{B}
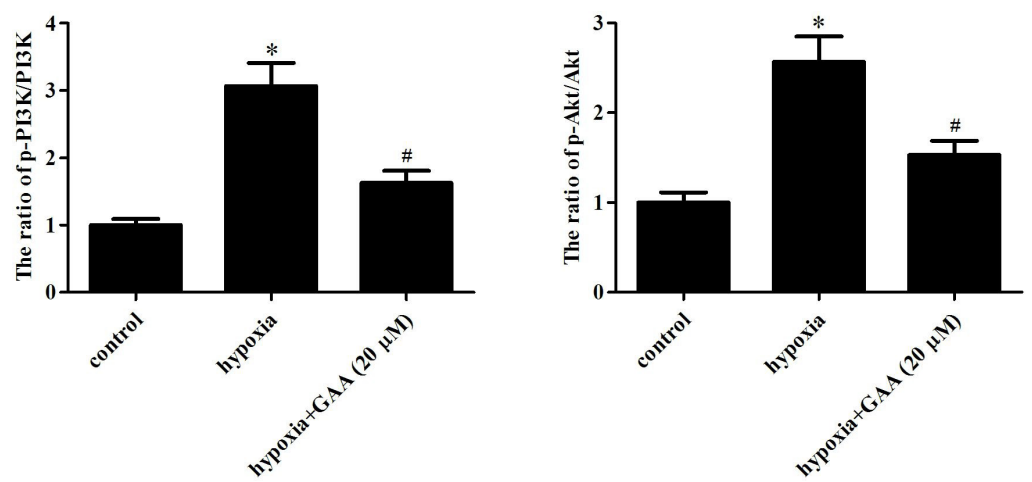

Figure 4. GAA inhibits the activation of PI3K/Akt in PASMCs in response to hypoxia. PASMCs were treated with $20 \mu \mathrm{M}$ GAA for $24 \mathrm{~h}$ then exposed to hypoxia condition. (A) The expression levels of PI3K, p-PI3K, Akt, and p-Akt in different groups were detected by western blot analysis; (B) The ratio of $\mathrm{p}$-PI3K/PI3K; (C) The ratio of $\mathrm{p}$-Akt/Akt. ${ }^{*} p<0.05$ versus control group; ${ }^{*} p<0.05$ versus hypoxia-treated group. 
A
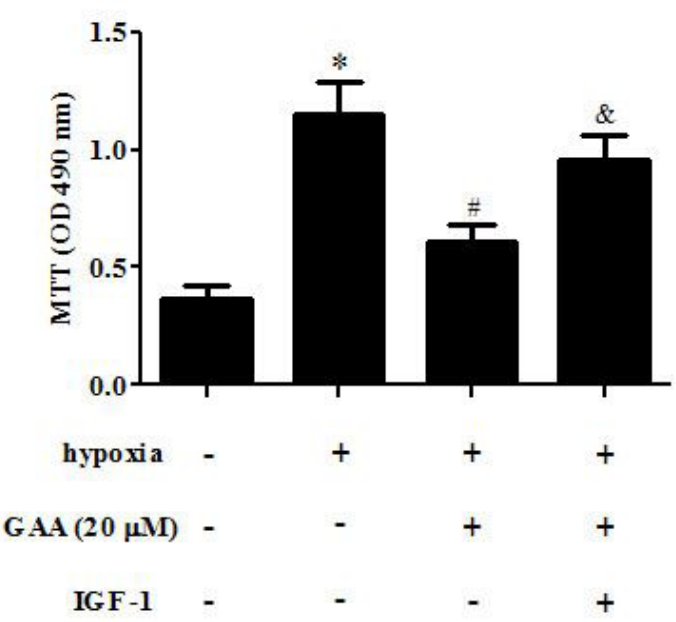

C

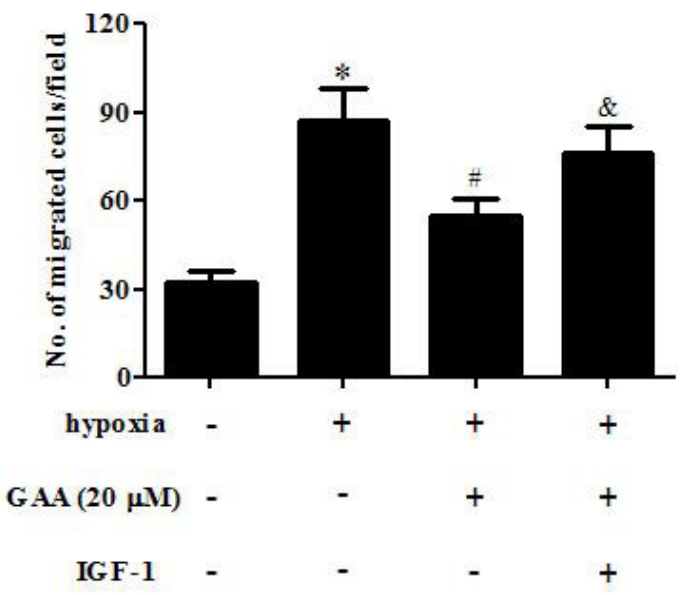

B
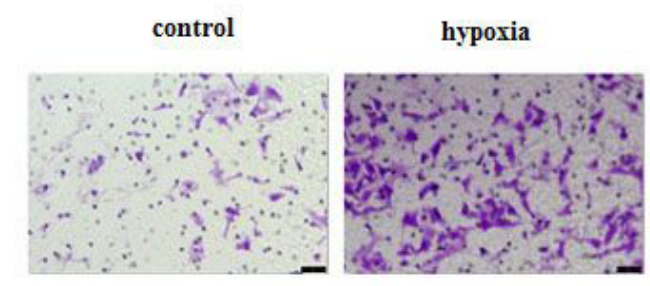

hypoxia + GAA

hypoxia+GAA+IGF-1

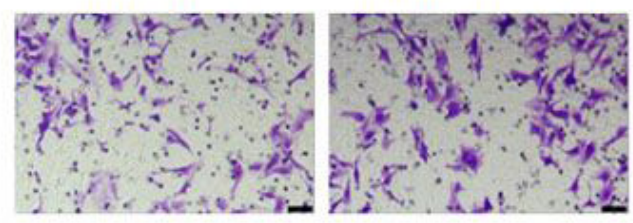

D

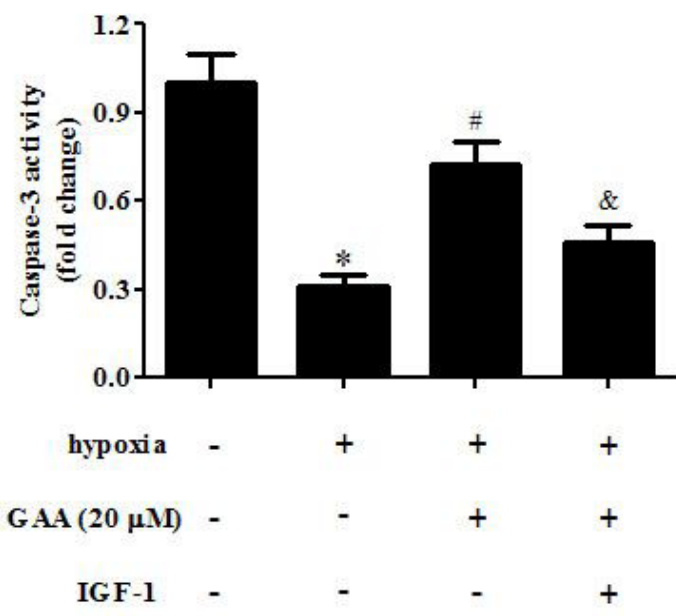

Figure 5. IGF-1 treatment reverses the effects of GAA on proliferation, migration and apoptosis in hypoxia-treated PASMCs. PASMCs were treated with $20 \mu \mathrm{M}$ GAA for $24 \mathrm{~h}$ in the presence of IGF-1 $(10 \mathrm{ng} / \mathrm{ml})$, and then exposed to hypoxia condition. (A) MTT assay for the proliferation of PASMCs; (B and C) Transwell assay for the migration of PASMCs; (D) Relative caspase-3 activity was detected using caspase-3 activity ELISA kit. ${ }^{\star} p<0.05$ versus control group; ${ }^{*} p<0.05$ versus hypoxia-treated group; ${ }^{*} p<0.05$ versus hypoxia+GAA group.

GAA on cell migration and apoptosis in PASMCs in response to hypoxia condition (Figures 5B-D).

\subsection{IGF-1 treatment reverses the effect of GAA on dedifferentiation of PASMCs}

Moreover, the results of western blot analysis demonstrated that IGF-1 treatment caused significant decreases in the protein expression levels of myocardin and calponin, and an increase in the protein expression level of OPN, as compared to the hypoxia+GAA group (Figure 6A-D).

\section{Discussion}

In the current study, we investigated the effect of GAA on PASMCs in response to hypoxia and uncovered the involved transduction pathway. Our results showed that hypoxia caused significant increases in the cell proliferation, migration and a decrease in cell apoptosis, which were blocked by GAA treatment. In addition, hypoxia-induced dedifferentiation of PASMCs was prevented by GAA. The effects of GAA on hypoxia-induced PASMCs were attributed to the PI3K/Akt signaling pathway.

ASMCs phenotypic modulation is characterized by reversible switching between contractile and proliferative phenotypes (Qi et al., 2019). Recently, it has been demonstrated that the phenotypic transition of PASMCs from a contractile/differentiated to synthetic/ de-differentiated phenotype is an important mechanism for the occurrence and development of hypoxic PAH (Luo et al., 2019; Papp et al., 2019; Peng et al., 2014). Under hypoxia condition, ASMCs change from contractile phenotype to a synthetic phenotype, thereby resulting in increased proliferative ability, migrative 
A

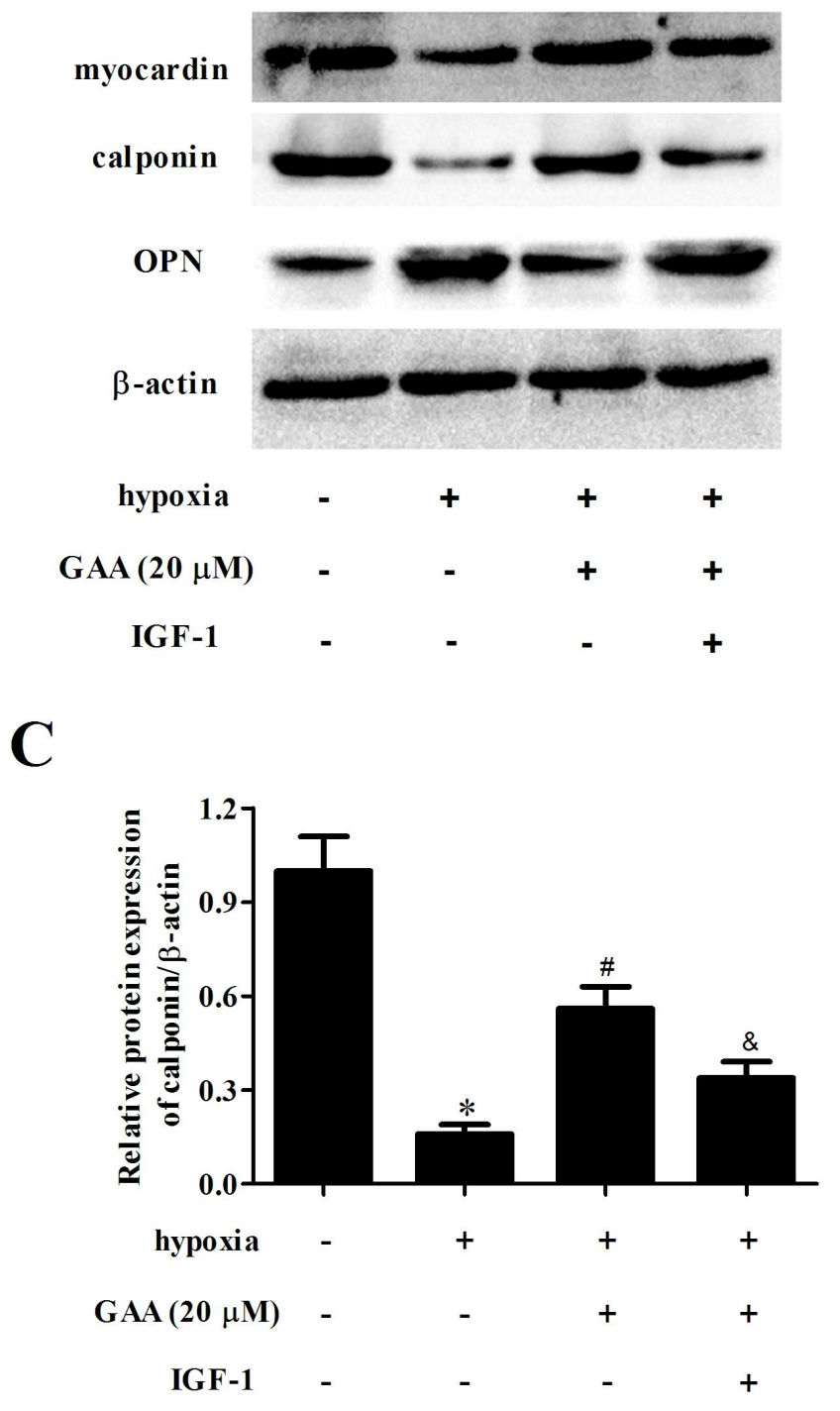

B

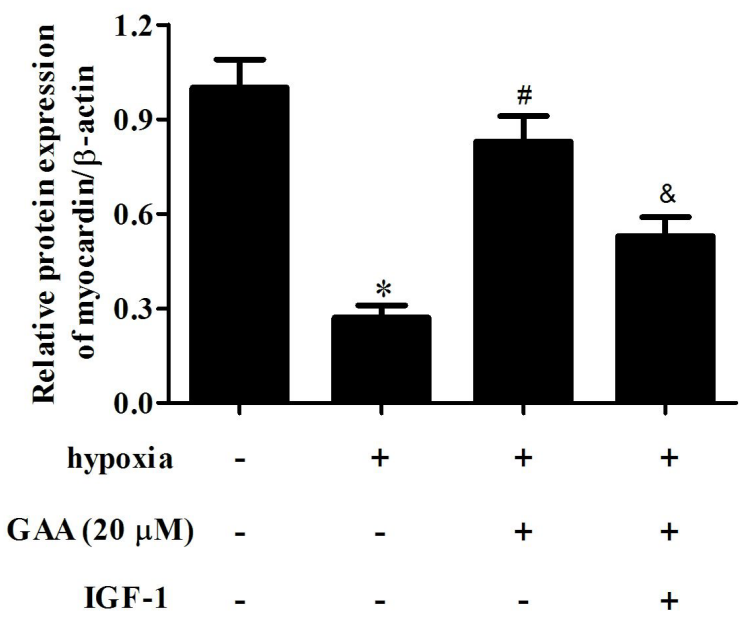

D

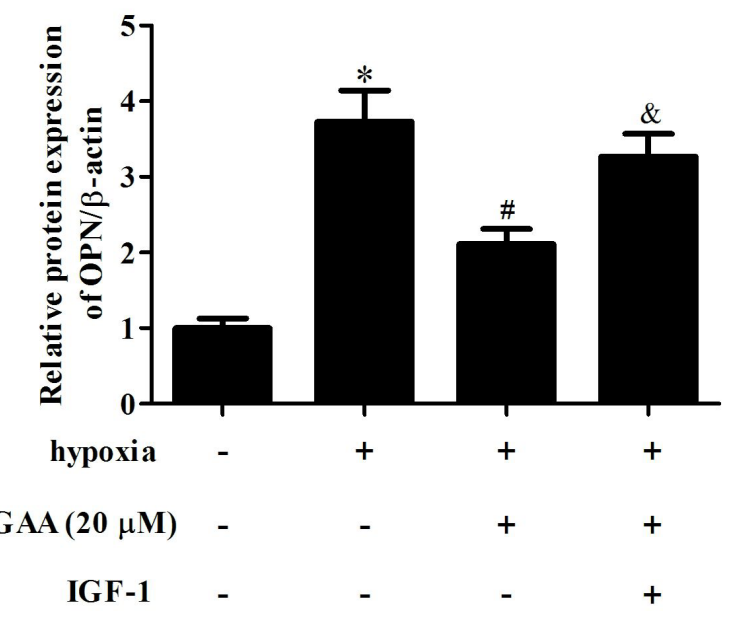

Figure 6. IGF- 1 treatment reverses the effect of GAA on hypoxia-induced dedifferentiation of PASMCs. PASMCs were treated with $20 \mu \mathrm{M}$ GAA for $24 \mathrm{~h}$ in the presence of IGF-1 $(10 \mathrm{ng} / \mathrm{ml})$, and then exposed to hypoxia condition. (A) Western blot analysis for the relative protein levels of contractile phenotype markers myocardin and calponin and synthetic phenotype marker OPN; (B-D) Quantification analysis of myocardin, calponin and OPN. ${ }^{*} p<0.05$ versus control group; ${ }^{*} p<0.05$ versus hypoxia-treated group; ${ }^{*} p<0.05$ versus hypoxia+GAA group.

ability, ECM accumulation, and finally leading to endometrial hyperplasia and vascular remodeling (Davis-Dusenbery et al., 2011; Qi et al., 2019; Zhang et al., 2016). In the current study, we found that hypoxia-induced proliferative and migrative ability of PASMCs were prevented by GAA. GAA treatment significantly attenuated the hypoxia-induced downregulation of the expression of contractile phenotype marker proteins including myocardin and calponin, and upregulation of the expression of synthetic phenotype marker protein OPN. These results indicated that hypoxia-induced phenotype modulation of PASMCs was blocked by GAA.

Advances in researches on the signaling pathways for phenotypic modulation of PASMCs in hypoxia have highlighted the importance of various transductions, such as signal transduces and activators of transcription (STAT), protein kinase $\mathrm{C}(\mathrm{PKC})$ mitogen-activated protein kinase (MAPK), PI3K/Akt, cyclic guanosine monophosphate (cGMP)/protein kinase G (PKG), cyclic adenosine monophosphate (c-AMP)/phosphodiesterase (PDE) (Hong et al., 2017; Peng et al., 2019; Yeo et al., 2020; Yi et al., 2012b; Yin et al., 2011). Among these signaling, PI3K/ Akt is a well-studied pathway hyperactivated or altered in many types of diseases and regulates a broad range of cellular processes, such as differentiation, survival, growth, proliferation, metabolism, angiogenesis and metastasis (Ersahin et al., 2015; Follo et al., 2015; Xu et al., 2020). Previous studies have found that PI3K/Akt pathway plays a vital role in the modulation of 
PASMCs cytoskeleton rearrangement and phenotype switching (Fan et al., 2014; Yi et al., 2012a). Treatment of PASMCs with platelet-derived growth factor (PDGF)-BB induces cytoskeleton rearrangements and downregulates contractile phenotype marker proteins (SM22 $\alpha$ and $\alpha$-SM actin). Inhibition of PI3K/Akt attenuates the PDGF-BB-induced downregulation of contractile phenotype markers (Fan et al., 2014).

Increasing evidences have shown that GAA has regulatory effect on the activation of PI3K/Akt signaling pathway in various pathological conditions. Cheng et al. (Cheng \& Xie, 2019) demonstrated that GAA holds promising cytotoxicity on human glioblastoma, which is mediated by incurring apoptosis and autophagy and inactivating PI3K/Akt signaling pathway. GAA partially contributes to suppress high-grade meningioma growth via altering of PI3K/Akt signaling pathway (Das et al., 2020). GAA exhibits protective functions in lens epithelial cells and rat lenses against UVB-evoked impairment through activating the PI3K/Akt pathway (Kang et al., 2020). GAA protects rat $\mathrm{H} 9 \mathrm{c} 2$ cardiomyocytes from hypoxia-induced injury via downregulating PTEN and activating PI3K/Akt signaling pathway (Zhang et al., 2018). Thus, we evaluated whether PI3K/Akt pathway was involved in the effect of GAA on hypoxia-induced PASMCs. The results showed that hypoxia-induced activation of PI3K/Akt pathway was suppressed by GAA. Activation of PI3K/ Akt pathway by IGF-1 reversed the effect of GAA on the hypoxiainduced PASMCs phenotypic modulation, which indicated that the effect of GAA was mediated by PI3K/Akt pathway.

In conclusion, these findings demonstrated that GAA treatment prevented hypoxia-induced phenotypic modulation of PASMCs through the inactivation of PI3K/Akt pathway in $\mathrm{PAH}$. Hence, GAA may be a potent therapeutic agent for PAH in future clinical practice.

\section{Conflict of interest}

None.

\section{Acknowledgements}

This study was supported by the Natural Science Foundation of Shaanxi Province in China (2018JQ8044).

\section{References}

Ahmad, M. F. (2018). Ganoderma lucidum: persuasive biologically active constituents and their health endorsement. Biomedicine and Pharmacotherapy, 107, 507-519. http://dx.doi.org/10.1016/j. biopha.2018.08.036. PMid:30114634.

Awdish, R., \& Cajigas, H. (2016). Definition, epidemiology and registries of pulmonary hypertension. Heart Failure Reviews, 21(3), 223-228. http://dx.doi.org/10.1007/s10741-015-9510-y. PMid:26438630.

Barman, S. A., \& Marrero, M. B. (2005). Mechanism of endothelin-1 activation of MAP kinases in neonatal pulmonary vascular smooth muscle. Lung, 183(6), 425-439. http://dx.doi.org/10.1007/s00408005-2554-3. PMid:16465602.

Cheng, Y., \& Xie, P. (2019). Ganoderic acid A holds promising cytotoxicity on human glioblastoma mediated by incurring apoptosis and autophagy and inactivating PI3K/AKT signaling pathway. Journal of Biochemical and Molecular Toxicology, 33(11), e22392. http:// dx.doi.org/10.1002/jbt.22392. PMid:31503386.

Chi, B., Wang, S., Bi, S., Qin, W., Wu, D., Luo, Z., Gui, S., Wang, D., Yin, X., \& Wang, F. (2018). Effects of ganoderic acid A on lipopolysaccharide-induced proinflammatory cytokine release from primary mouse microglia cultures. Experimental and Therapeutic Medicine, 15(1), 847-853. PMid:29399089.

Coons, J. C., Pogue, K., Kolodziej, A. R., Hirsch, G. A., \& George, M. P. (2019). Pulmonary Arterial Hypertension: a pharmacotherapeutic update. Current Cardiology Reports, 21(11), 141. http://dx.doi. org/10.1007/s11886-019-1235-4. PMid:31758342.

Dai, J., Zhou, Q., Chen, J., Rexius-Hall, M. L., Rehman, J., \& Zhou, G. (2018). Alpha-enolase regulates the malignant phenotype of pulmonary artery smooth muscle cells via the AMPK-Akt pathway. Nature Communications, 9(1), 3850. http://dx.doi.org/10.1038/ s41467-018-06376-x. PMid:30242159.

Das, A., Alshareef, M., Henderson, F. Jr, Santos, J. L. M., Vandergrift, W. A. 3rd, Lindhorst, S. M., Varma, A. K., Infinger, L., Patel, S. J., \& Cachia, D. (2020). Ganoderic acid A/DM-induced NDRG2 overexpression suppresses high-grade meningioma growth. Clinical \& Translational Oncology, 22(7), 1138-1145. http://dx.doi.org/10.1007/ s12094-019-02240-6. PMid:31732915.

Davis-Dusenbery, B. N., Wu, C., \& Hata, A. (2011). Micromanaging vascular smooth muscle cell differentiation and phenotypic modulation. Arteriosclerosis, Thrombosis, and Vascular Biology, 31(11), 2370-2377. http://dx.doi.org/10.1161/ATVBAHA.111.226670. PMid:22011749.

Ersahin, T., Tuncbag, N., \& Cetin-Atalay, R. (2015). The PI3K/AKT/ mTOR interactive pathway. Molecular BioSystems, 11(7), 1946-1954. http://dx.doi.org/10.1039/C5MB00101C. PMid:25924008.

Fan, Z., Li, C., Qin, C., Xie, L., Wang, X., Gao, Z., Qiangbacuozhen, Wang, T., Yu, L., \& Liu, H. (2014). Role of the PI3K/AKT pathway in modulating cytoskeleton rearrangements and phenotype switching in rat pulmonary arterial vascular smooth muscle cells. DNA and Cell Biology, 33(1), 12-19. http://dx.doi.org/10.1089/dna.2013.2022. PMid:24283363.

Follo, M. Y., Manzoli, L., Poli, A., McCubrey, J. A., \& Cocco, L. (2015). $\mathrm{PLC}$ and PI3K/Akt/mTOR signalling in disease and cancer. Advances in Biological Regulation, 57, 10-16. http://dx.doi.org/10.1016/j. jbior.2014.10.004. PMid:25482988.

Gill, B. S., Navgeet, \& Kumar, S. (2016). Ganoderic acid targeting multiple receptors in cancer: in silico and in vitro study. Tumour Biology, 37(10), 14271-14290. http://dx.doi.org/10.1007/s13277016-5291-8. PMid:27592256.

He, S., Zhu, T., \& Fang, Z. (2020). The role and regulation of Pulmonary Artery Smooth Muscle Cells in pulmonary hypertension. International Journal of Hypertension, 2020, 1478291. http://dx.doi. org/10.1155/2020/1478291. PMid:32850144.

Hong, Z., Chen, K. H., DasGupta, A., Potus, F., Dunham-Snary, K., Bonnet, S., Tian, L., Fu, J., Breuils-Bonnet, S., Provencher, S., Wu, D., Mewburn, J., Ormiston, M. L., \& Archer, S. L. (2017). MicroRNA-138 and MicroRNA-25 down-regulate mitochondrial calcium uniporter, causing the Pulmonary Arterial Hypertension cancer phenotype. American Journal of Respiratory and Critical Care Medicine, 195(4), 515-529. http://dx.doi.org/10.1164/rccm.2016040814OC. PMid:27648837.

Hu, J., Xu, Q., McTiernan, C., Lai, Y. C., Osei-Hwedieh, D., \& Gladwin, M. (2015). Novel targets of drug treatment for Pulmonary Hypertension. American Journal of Cardiovascular Drugs, 15(4), 225-234. http:// dx.doi.org/10.1007/s40256-015-0125-4. PMid:26016608.

Kang, L. H., Zhang, G. W., Zhang, J. F., Qin, B., \& Guan, H. J. (2020). Ganoderic acid A protects lens epithelial cells from UVB irradiation 
and delays lens opacity. Chinese Journal of Natural Medicines, 18(12), 934-940. http://dx.doi.org/10.1016/S1875-5364(20)600371. PMid:33357724.

Lan, N. S. H., Massam, B. D., Kulkarni, S. S., \& Lang, C. C. (2018). Pulmonary Arterial Hypertension: pathophysiology and treatment. Diseases, 6(2), 38. http://dx.doi.org/10.3390/diseases6020038. PMid:29772649.

Luo, Y., Teng, X., Zhang, L., Chen, J., Liu, Z., Chen, X., Zhao, S., Yang, S., Feng, J., \& Yan, X. (2019). CD146-HIF-1alpha hypoxic reprogramming drives vascular remodeling and pulmonary arterial hypertension. Nature Communications, 10(1), 3551. http://dx.doi. org/10.1038/s41467-019-11500-6. PMid:31391533.

Montani, D., Chaumais, M. C., Guignabert, C., Gunther, S., Girerd, B., Jais, X., Algalarrondo, V., Price, L. C., Savale, L., Sitbon, O., Simonneau, G., \& Humbert, M. (2014). Targeted therapies in pulmonary arterial hypertension. Pharmacology \& Therapeutics, 141(2), 172-191. http:// dx.doi.org/10.1016/j.pharmthera.2013.10.002. PMid:24134901.

Papp, R., Nagaraj, C., Zabini, D., Nagy, B. M., Lengyel, M., Maurer, D. S., Sharma, N., Egemnazarov, B., Kovacs, G., Kwapiszewska, G., Marsh, L. M., Hrzenjak, A., Hofler, G., Didiasova, M., Wygrecka, M., Sievers, L. K., Szucs, P., Enyedi, P., Ghanim, B., Klepetko, W., Olschewski, H., \& Olschewski, A. (2019). Targeting TMEM16A to reverse vasoconstriction and remodelling in idiopathic pulmonary arterial hypertension. The European Respiratory Journal, 53(6), 1800965. http://dx.doi.org/10.1183/13993003.00965-2018. PMid:31023847.

Peng, X., Li, H. X., Shao, H. J., Li, G. W., Sun, J., Xi, Y. H., Li, H. Z., Wang, X. Y., Wang, L. N., Bai, S. Z., Zhang, W. H., Zhang, L., Yang, G. D., Wu, L. Y., Wang, R., \& Xu, C. Q. (2014). Involvement of calcium-sensing receptors in hypoxia-induced vascular remodeling and pulmonary hypertension by promoting phenotypic modulation of small pulmonary arteries. Molecular and Cellular Biochemistry, 396(1-2), 87-98. http://dx.doi.org/10.1007/s11010-014-2145-9. PMid:25063217.

Peng, X., Wei, C., Li, H. Z., Li, H. X., Bai, S. Z., Wang, L. N., Xi, Y. H., Yan, J., \& Xu, C. Q. (2019). NPS2390, a selective calcium-sensing receptor antagonist controls the phenotypic modulation of hypoxic human Pulmonary Arterial Smooth Muscle Cells by regulating autophagy. Journal of Translational Internal Medicine, 7(2), 59-68. http://dx.doi.org/10.2478/jtim-2019-0013. PMid:31380238.

Qi, Y., Dai, F., Gu, J., \& Yao, W. (2019). Biomarkers in VSMC phenotypic modulation and vascular remodeling. Die Pharmazie, 74(12), 711714. PMid:31907108.

Sanodiya, B. S., Thakur, G. S., Baghel, R. K., Prasad, G. B., \& Bisen, P. S. (2009). Ganoderma lucidum: a potent pharmacological macrofungus. Current Pharmaceutical Biotechnology, 10(8), 717-742. http://dx.doi. org/10.2174/138920109789978757. PMid:19939212.
Veith, C., Schermuly, R. T., Brandes, R. P., \& Weissmann, N. (2016). Molecular mechanisms of hypoxia-inducible factor-induced pulmonary arterial smooth muscle cell alterations in pulmonary hypertension. The Journal of Physiology, 594(5), 1167-1177. http:// dx.doi.org/10.1113/JP270689. PMid:26228924.

Xu, F., Na, L., Li, Y., \& Chen, L. (2020). Roles of the PI3K/AKT/mTOR signalling pathways in neurodegenerative diseases and tumours. Cell \& Bioscience, 10(1), 54. http://dx.doi.org/10.1186/s13578-02000416-0. PMid:32266056.

Yeo, Y., Yi, E. S., Kim, J. M., Jo, E. K., Seo, S., Kim, R. I., Kim, K. L., Sung, J. H., Park, S. G., \& Suh, W. (2020). FGF12 (Fibroblast Growth Factor 12) inhibits vascular smooth muscle cell remodeling in Pulmonary Arterial Hypertension. Hypertension, 76(6), 1778-1786. http://dx.doi. org/10.1161/HYPERTENSIONAHA.120.15068. PMid:33100045.

Yi, B., Cui, J., Ning, J. N., Wang, G., Qian, G., \& Lu, K. (2012a). Overexpression of PKGIalpha inhibits hypoxia-induced proliferation, Akt activation, and phenotype modulation of human PASMCs: the role of phenotype modulation of PASMCs in pulmonary vascular remodeling. Gene, 492(2), 354-360. http://dx.doi.org/10.1016/j. gene.2011.11.010. PMid:22101188.

Yi, B., Cui, J., Ning, J., Gu, J., Wang, G., Bai, L., Qian, G., \& Lu, K. (2012b). cGMP-dependent protein kinase Ialpha transfection inhibits hypoxia-induced migration, phenotype modulation and annexins A1 expression in human pulmonary artery smooth muscle cells. Biochemical and Biophysical Research Communications, 418(4), 598602. http://dx.doi.org/10.1016/j.bbrc.2012.01.034. PMid:22293199.

Yin, H., Li, Q., Qian, G., Wang, Y., Li, Y., Wu, G., \& Wang, G. (2011). Rab1 GTPase regulates phenotypic modulation of pulmonary artery smooth muscle cells by mediating the transport of angiotensin II type 1 receptor under hypoxia. The International Journal of Biochemistry \& Cell Biology, 43(3), 401-408. http://dx.doi.org/10.1016/j. biocel.2010.11.010. PMid:21095238.

Zhang, M. J., Zhou, Y., Chen, L., Wang, Y. Q., Wang, X., Pi, Y., Gao, C. Y., Li, J. C., \& Zhang, L. L. (2016). An overview of potential molecular mechanisms involved in VSMC phenotypic modulation. Histochemistry and Cell Biology, 145(2), 119-130. http://dx.doi. org/10.1007/s00418-015-1386-3. PMid:26708152.

Zhang, X., Xiao, C., \& Liu, H. (2018). Ganoderic acid A protects rat $\mathrm{H} 9 \mathrm{c} 2$ cardiomyocytes from hypoxia-induced injury via up-regulating miR-182-5p. Cellular Physiology and Biochemistry, 50(6), 2086-2096. http://dx.doi.org/10.1159/000495053. PMid:30415259.

Zhang, Y., Shi, K., Lin, T., Xia, F., Cai, Y., Ye, Y., Liu, L., \& Liu, F. (2020). Ganoderic acid A alleviates myocardial ischemia-reperfusion injury in rats by regulating JAK2/STAT3/NF-kappaB pathway. International Immunopharmacology, 84, 106543. http://dx.doi.org/10.1016/j. intimp.2020.106543. PMid:32353688. 